\title{
SOYBEAN EVAPOTRANSPIRATION, LEAF WATER POTENTIAL AND FOLIAGE TEMPERATURE AS AFFECTED BY ROW SPACING AND IRRIGATION
}

\author{
D.C. REICOSKY ${ }^{1}$, D.D. WARNES ${ }^{2}$, and S.D. EVANS ${ }^{3}$
}

\author{
${ }^{1}$ Agricultural Research Service, USDA, Morris, MN 56267 (U.S.A.) \\ Department of Agronomy ${ }^{2}$, Department of Soil Science, ${ }^{3}$, University of Minnesota, \\ Morris, MN 56267 (U.S.A.)
}

Contribution from the North Central Soil Conservation Research Laboratory, Agricultural Research Service, USDA, Morris, MN 56267, in cooperation with the Minnesota Agricultural Experiment Station, Scientific Journal Series No. 13,033.

(Accepted 28 August 1984)

\section{ABSTRACT}

Reicosky, D.C., Warnes, D.D. and Evans, S.D., 1985. Soybean evapotranspiration, leaf water potential and foliage temperature as affected by row spacing and irrigation. Field Crops Res., 10: 37-48.

Information is needed on the effects of soybean row spacing as a management practice for improving water use efficiency. Our objective was to show the effect of soybean (Glycine max (L.) Merr. cv. 'Evans') row spacing and irrigation on evapotranspiration (ET), leaf water potential $\left(\psi_{\ell}\right)$, and foliage temperatures (TF) in western Minnesota.

Soybeans were planted in $0.15-$ and $0.46-\mathrm{m}$ rows with a grain drill, and $0.76-\mathrm{m}$ rows with a row crop planter at an average final population of 571000 plants per ha on a Sioux sandy loam (Family sandy skeletal mixed, subgroup Udorthentic Haploboroll). Sprinkler irrigation was applied in $25-\mathrm{mm}$ amounts to the irrigated plots when the average matric potential at the $0.3-\mathrm{m}$ depth was $-30 \mathrm{kPa}$.

On selected days in the growing season, measurements of ET using a portable chamber, $\psi_{\ell}$ using the pressure chamber, TF using an infrared thermometer, and dry (TA) and wet (TW) bulb temperatures using an aspirated psychrometer were made simultaneously on a given treatment. Hourly weather data were collected $2.2 \mathrm{~km}$ from the experimental site to characterize the daily climate and evaporative demand. Leaf area index and light interception by the canopy were determined in 7-to 10-day intervals.

Early in the season ET on the non-irrigated plots was slightly higher for the $0.15-\mathrm{m}$ row spacing than the 0.46 - and $0.76-\mathrm{m}$ row spacing and was related to light interception. Differences in midday $\psi \ell$ due to row spacing were not discernible due to scatter in the data, and only with severe water stress were the $\psi \ell$ differences due to irrigation noteworthy. The row spacings effects on the TF-TA differences agreed with the ET trends on the non-irrigated plots. Only the yield differences due to irrigation were significant. For the irrigated treatments, the yields were $3.35,3.09,3.07 \mathrm{t} / \mathrm{ha}$ for the $0.15-, 0.46-$, and 0.76-m row spacings, respectively, while the corresponding yields for the non-irrigated treatments were $2.07,1.97,2.24 \mathrm{t} / \mathrm{ha}$.

Trade names and company names are included for the benefit of the reader and do not infer any endorsement or preferential treatment of the product listed by the U.S. Department of Agriculture or the University of Minnesota. 


\section{INTRODUCTION}

Interest in modifying soybean row spacings for increasing soybean yields has been renewed because it is one practical management factor that can be controlled easily. The plant distribution is more equidistant in narrow rows and plants more quickly occupy the narrow row environment than do plants in the wide row plantings. Recent trials in the Midwestern U.S.A. indicated that soybean yields were higher in narrower rows than in historical $1.02 \mathrm{~m}$ spacings (Pendleton et al., 1960; Cooper and Lambert, 1965; Weber et al., 1966; and Cooper, 1977). The yield increase at the same plant population was attributed to the development of a canopy that provided complete ground cover in narrow rows by the time of rapid pod fill (Shibles and Weber, 1965).

Full ground cover canopies intercept more solar radiation and give greater photosynthesis than do partial ground covered canopies (Shibles and Weber, 1965, 1966). Rapid canopy development may be a disadvantage during dry years, however, because the increased early season exposure of leaves to full sunlight increases use of stored soil water if all other factors are equal. If more stored water is used early in the season then less water is available during the critical pod filling period. Taylor (1980) found that during a year when the water supply was high, narrow-row $(0.25 \mathrm{~m})$ soybeans yielded $17 \%$ more than those in $1.0-\mathrm{m}$ row spacings. However, during years with low seasonal water supplies, there were no significant differences in the yields among any of the row spacings.

In the northern regions of the soybean growing area, row spacing experiments gave different results. Timmons et al. (1967) found that evapotranspiration differences between row spacings and populations were small and water use efficiency values for each year in the study were within a relatively narrow range. Higher water use efficiencies were obtained for low plant population in narrow rows. In a drier region, Alessi and Power (1982) found no effect of row spacing on soybean yields in years of normal or above normal precipitation. They did observe reduction in yield when there was severe water stress encountered during years of below normal precipitation. The data suggested narrow rows may be beneficial for soybean production when water is not restricting, i.e., with irrigation. Somewhat conflicting results have been reported by Safo-Kantanka and Lawson (1980) in Canada. While they observed a trend of decreasing yields as row width increased this decrease was not significant. They indicated that slight yield increase with narrow rows may be due to more uniform distribution of light within the canopies.

In view of the conflicting reports on the effects of row spacing in the northern soybean area, an experiment was designed to determine the effect of row spacing and irrigation on soybean production in west central Minnesota, U.S.A. Our objective was to determine the effect of row spacing and irrigation on evapotranspiration, leaf water potential, and canopy temperatures for soybeans grown on a sandy loam soil. 


\section{MATERIALS AND METHODS}

This experiment was conducted in 1980 on a Sioux sandy loam (Family sandy skeletal mixed, subgroup Udorthentic Haploboroll) on the West Central Experiment Station of the University of Minnesota at Morris, MN $\left(45^{\circ} 35^{\prime} \mathrm{N}\right.$ latitude and $95^{\circ} 55^{\prime} \mathrm{W}$ longitude). The soil is characterized by 0.46 $\mathrm{m}$ of sandy loam material overlying very coarse gravel with available water holding capacity less than $60 \mathrm{~mm}$ in the $0.46-\mathrm{m}$ rooting depth. Droughty conditions frequently exist because of shallow root development, low water holding capacity, and erratic rainfall.

The experiment consisted of three different row spacings replicated four times in a randomized complete block with split plots with irrigation as main plots and row spacing as subplot randomly assigned within main plots. Evans soybeans (Group 0 maturity) were planted on 16 May 1980 (Day of Year (DY) 137) in 0.15 and $0.46 \mathrm{~m}$ rows with a grain drill and $0.76-\mathrm{m}$ rows with a row crop planter at an average final population of 571000 plants per ha and harvested with a plot combine on 7 October 1980 (DY 281). Individual plots were $6.1 \mathrm{~m} \times 15.2 \mathrm{~m}$ for all of the row spacings. One-half the plots were sprinkler irrigated in $25-\mathrm{mm}$ amounts when the matric potential at the $0.3-\mathrm{m}$ depth was $-30 \mathrm{kPa}$ as measured with tensiometers.

On selected days within the growing season, intensive measurements were made. Evapotranspiration (ET) measurements were made using a portable chamber technique described by Reicosky and Peters (1977). Photosynthetically active radiation (PAR) was measured at the same time as the ET measurement using a Li-Cor model LI-190SB quantum sensor and model LI-185B meter.

Leaf water potential $\left(\psi_{\ell}\right)$ was measured using a commercially available pressure chamber like that of Scholander et al. (1965). Foliage temperature (TF) was measured using a Teletemp model AG42 infrared thermometer, starting DY 206, held at oblique angles to the canopy (Idso et al., 1981). Duplicate measurements were made in the east-west direction and averaged to correspond to the ET and $\psi \ell$ measurements. Simultaneous measurements of wet (TW) and dry (TA) bulb temperatures at a height of $1.30 \mathrm{~m}$ were made using an aspirated psychrometer at the edge of the plot for calculation of the foliage-air temperature difference (TF-TA) and Ambient Vapor Pressure Deficit (AVPD). Measurements of ET, PAR, $\psi \ell, T F$, and AVPD were made simultaneously on a given plot.

In order to evaluate the effect of row spacing and irrigation on ET, $\psi_{\ell}$, and $\mathrm{TF}$, diurnal measurements were made at selected times during the growing season. Because measurements were made on one plot at a time and the measurements had to be made sequentially, treatment comparisons were made by averaging the values within the time interval between 11.00 and $15.00 \mathrm{~h}(\mathrm{CDT})$. In order to make treatment comparisons and to determine the seasonal trends, only the individual data points collected around solar noon ( 11.00 to $15.00 \mathrm{~h}$ CDT) were averaged to represent the midday values 
of these parameters. The number of data points in this time interval within these days of intensive measurements varied from 3 to 12 on any given treatment. The effect of intermittent clouds on the individual measurements was assumed to be random so the treatment averages can be compared. This assumption was reasonable with a large number of measurements during the 4 -h interval. However, with less than four measurements, its validity is questionable.

Leaf area index (LAI) and light interception data were obtained on each of the treatments periodically during the growing season. Light interception was measured using the LI-Cor Model LI-191SB light bar (1 $\mathrm{m} \mathrm{long}$ ) for measuring PAR. The light interception measurements were made by placing the light bar on leveled soil surface underneath the canopy and recording PAR, after which the light bar was brought above the canopy, leveled and the above canopy reading recorded. The ratio of the above canopy reading divided by the below canopy reading was used to calculate canopy light interception. Leaf area was measured on plants cut from $0.5 \mathrm{~m}$ of row. Individual leaflets were removed from the plants and leaf area measurements made using a LI-Cor Model LI-3000 leaf area meter. Data reported here were obtained from linear interpolation between the sampling dates for each of the dates sampled to correspond to the days of intensive ET measurements.

Hourly weather and open pan evaporation data were collected $2.2 \mathrm{~km}$ from the experimental site to characterize the daily climate and evaporative demand. During the periods of intensive measurement, these data were used to calculate potential evapotranspiration (PET) after van Bavel (1966) to determine the ratio of the ET to PET. Integrated hourly solar and net radiation $1.0 \mathrm{~m}$ over a well watered short grass were measured. Air temperature (TA), dew point temperature (TD) and wind speed were measured at a $2-\mathrm{m}$ height. Soil heat flux was measured at $50 \mathrm{~mm}$ below the surface. All data were collected hourly and used to calculate PET on an hourly basis. The roughness parameter $\left(Z_{0}\right)$ used in these calculations was assumed to be $5 \mathrm{~mm}$ for the short grass. The hourly values of PET were averaged for the 4-h interval for comparison with the experimental treatments.

\section{RESULTS AND DISCUSSION}

The total amount of rainfall (Fig. 1) during this season was near normal. However, the distribution was erratic. The cumulative rainfall from planting to harvest in 1980 was $401 \mathrm{~mm}$. The irrigation frequency (Fig. 1) shows water was applied approximately every 7-10 days in order to meet the tensiometer criteria that resulted in a total of $345 \mathrm{~mm}$ of water applied from planting to harvest. This amount of water was required because of the low water holding capacity of the soil.

Intensive measurements were initiated shortly after the canopies in the $0.15-\mathrm{m}$ row spacing treatment covered the soil 40 days after planting (DAP) 
(DY 177) and were continued periodically until 90 DAP (DY 277). At that time, intensive measurements were terminated for two reasons; first, because of significant rainfall on DY 230 and second, because the plants were starting to show signs of senescence associated with maturation as indicated by the lower leaves turning yellow.

The weather data for the days of intensive measurements collected at a weather station $2.2 \mathrm{~km}$ from the experimental site are summarized in Table I. Included are the daily values of solar radiation (RI) and PAR to indicate the extent of cloud cover and the key parameters in calculating the PET to show the day to day variation on the days of intensive measurement. The daily minimum TA was $8.6^{\circ} \mathrm{C}$ and the maximum was $32.8^{\circ} \mathrm{C}$. The daily PET ranged from 4.8 to $6.4 \mathrm{~mm} /$ day while the daily wind run ranged from 112 to $315 \mathrm{~km}$.

Leaf Area Index (LAI) (Fig. 2) measurements were initiated on DY 182 (45 DAP) and indicated that all three spacings and both water treatments reached a maximum LAI on about DY 204 (67 DAP). Scatter in the data suggested no significant difference due to the irrigation or row spacing on the LAI. The only noticeable difference was the slightly higher LAI on the
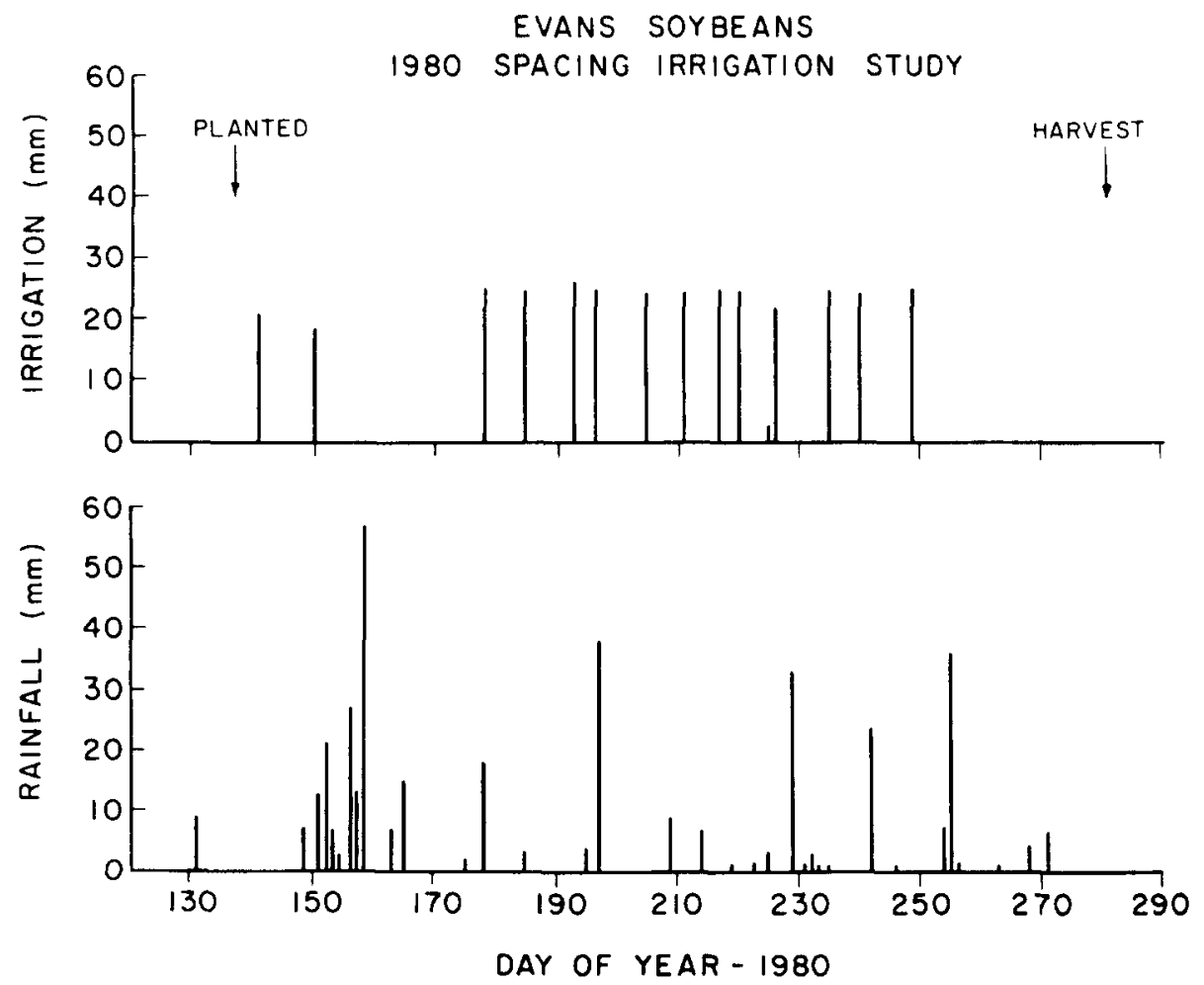

Fig. 1. Summary of the irrigation and rainfall during the 1980 growing season for the soybean spacing irrigation study. 


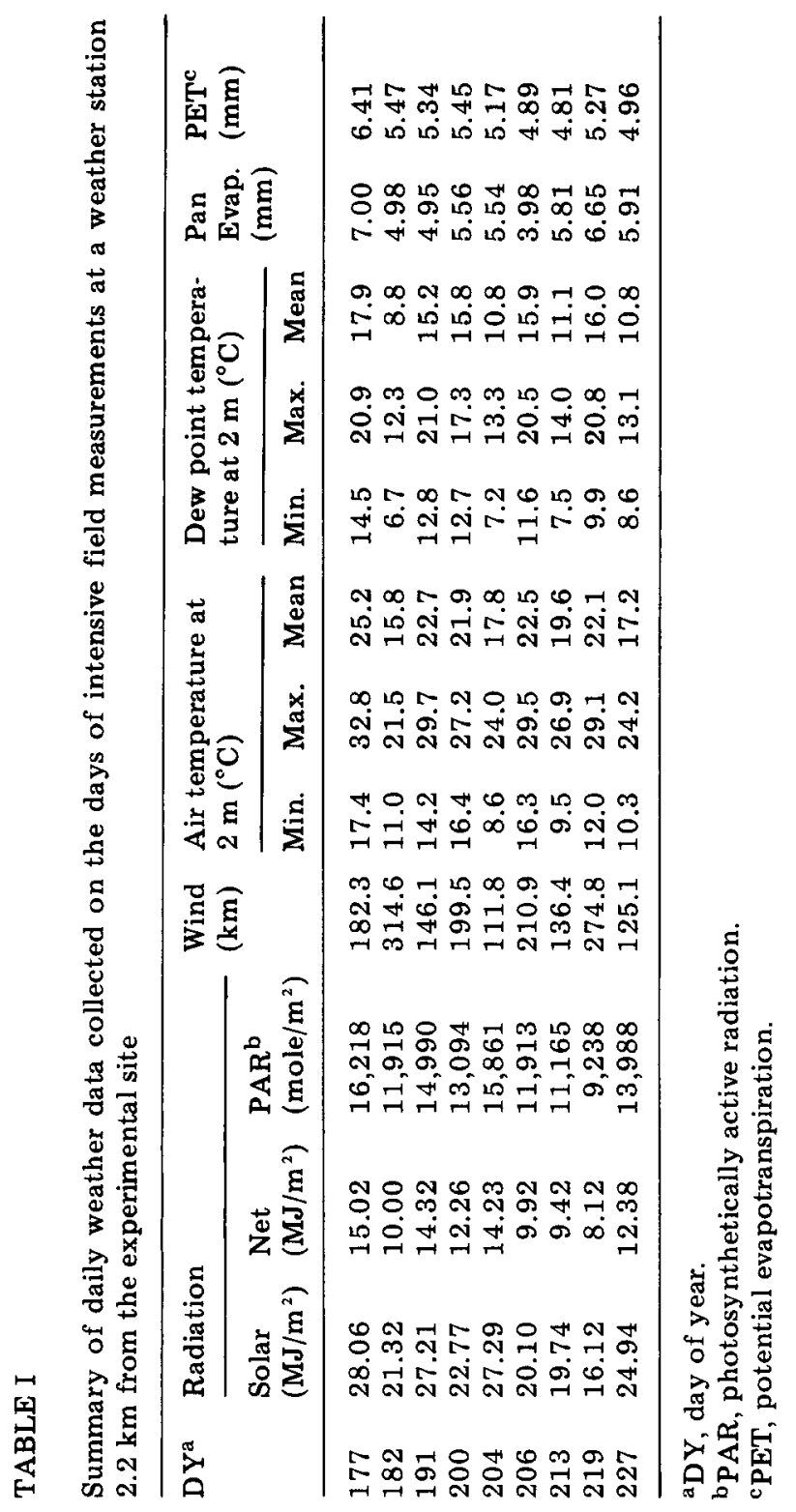




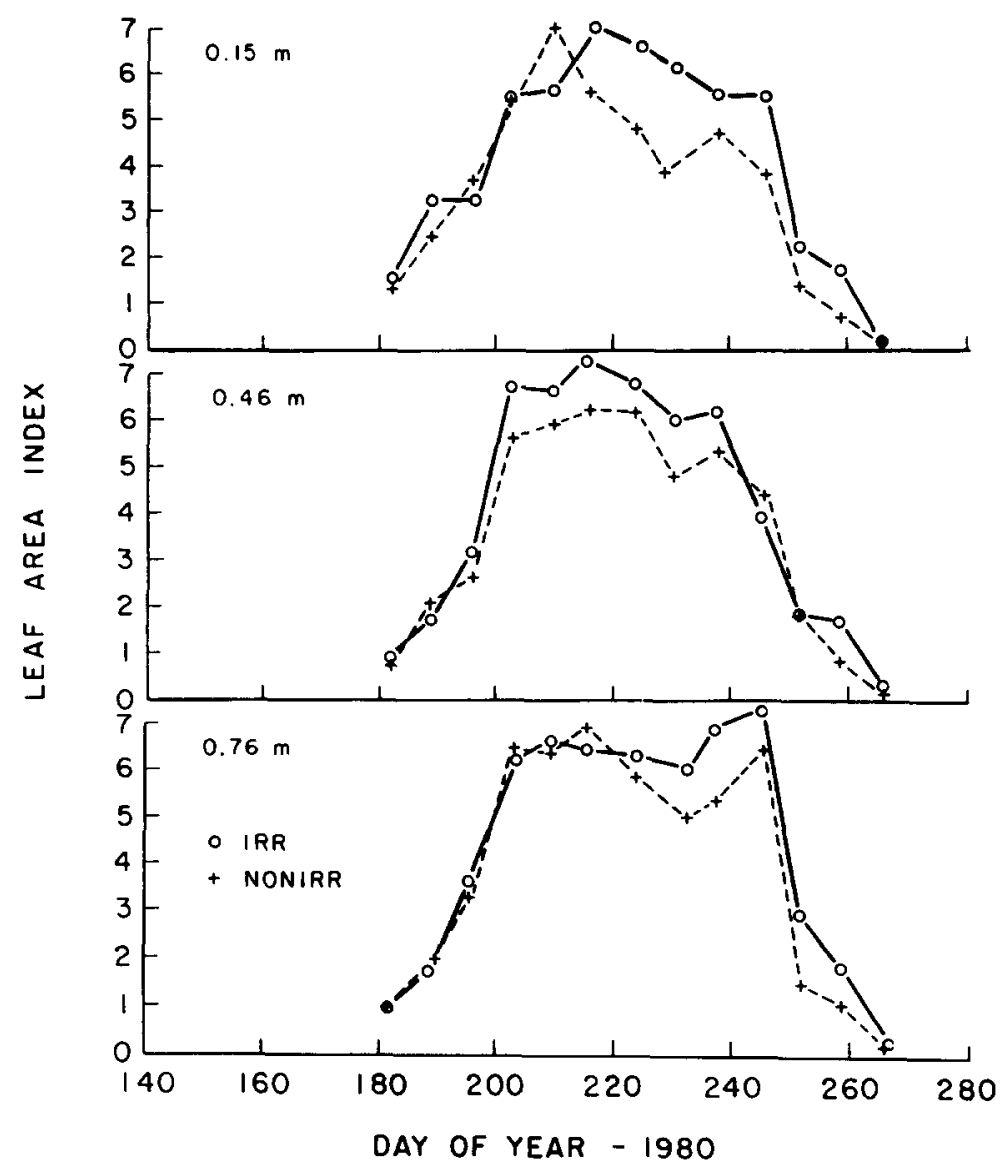

Fig. 2. Seasonal trends in leaf area index for the irrigated and non-irrigated Evans soybeans for the $0.15-, 0.46-$, and $0.76-\mathrm{m}$ row spacings.

$0.15-\mathrm{m}$ row spacing for both the irrigated and non-irrigated treatment on the first sampling. Measurements of light interception on the $0.15-\mathrm{m}$ row spacing indicated about $60 \%$ interception on DY 182 whereas the $0.76-\mathrm{m}$ row spacings intercepted about $30 \%$ of the light. This difference in light interception early in the season was the only noticeable difference due to row spacing throughout the entire growing season. More than $90 \%$ of the light was intercepted for all treatments shortly after DY 200 (64 DAP) which corresponded to about the same time that the maximum LAI was obtained.

The trend in the midday ET data for the three row spacings is summarized in Fig. 3. The ET was initially between 0.2 and $0.3 \mathrm{~mm} / \mathrm{h}$ on the $0.76-\mathrm{m}$ row spacing to a maximum of about $0.4 \mathrm{~mm} / \mathrm{h}$ on the $0.15-\mathrm{m}$ row spacing. The 
seasonal fluctuations were apparently related to the current evaporative demand and canopy development and showed an earlier separation between irrigated and non-irrigated on the $0.15-\mathrm{m}$ than on the $0.76-\mathrm{m}$ row spacing, with the $0.46-\mathrm{m}$ row spacing intermediate. The largest differences between the irrigated and the non-irrigated ET appeared shortly after DY 206 (69 DAP) as a result of the high water use rates and a minimum rainfall during this period. The low rainfall resulted in lower ET on the non-irrigated treatments between DY 206 and 227. The trend in the ratio of ET to PET was similar to that for ET alone and indicated the non-irrigated plots were under substantial stress late in the season (data not shown).

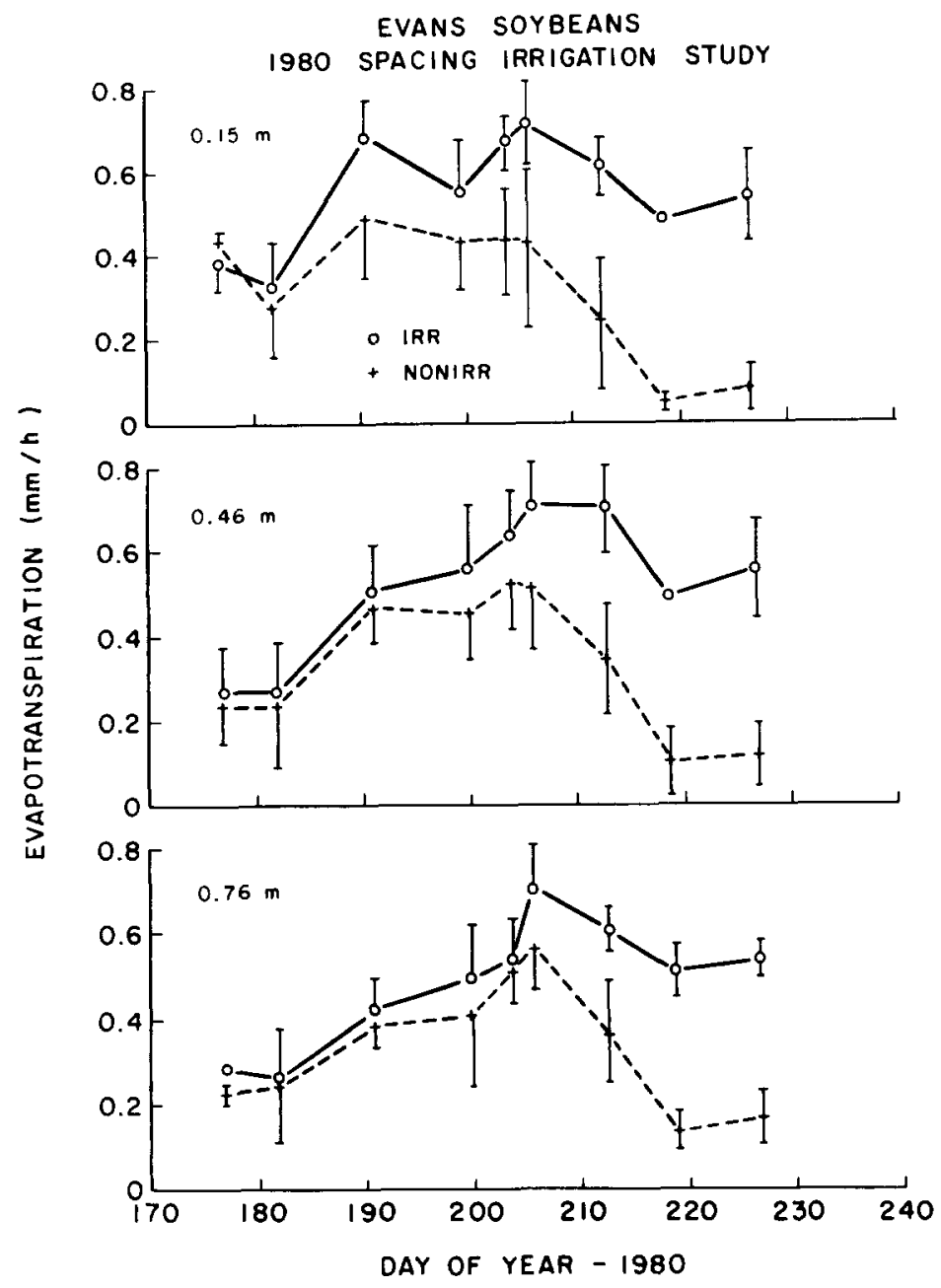

Fig. 3. Seasonal trends in the midday evapotranspiration plotted as the mean value of all those data points collected between 11.00 and $15.00 \mathrm{~h}$ CDT for the three row spacings. Vertical bars represent \pm one standard deviation with overlapping bars omitted for clarity. Symbols without vertical bars have the standard deviation contained within the symbol. 
The midday $\psi_{\ell}$ values obtained throughout the growing season are summarized in Fig. 4. The individual data points show considerable scatter which suggested there was no difference between the irrigated and non-irrigated treatments on any of the row spacings until the last sampling date (DY 227). On this day there had been 28 days where the cumulative rainfall was less than $22 \mathrm{~mm}$ in light showers that resulted in significant soil water stress in the non-irrigated treatments.

The midday TF-TA differences for each of the row spacings and in irrigation treatments are summarized in Fig. 5. There was some fluctuation in the midday values of TF-TA differential with a large separation later in the season as the drought stress become more severe. The extreme TF-TA differences ranged from -5.7 on the irrigated $0.15-\mathrm{m}$ row spacing to a maxi-

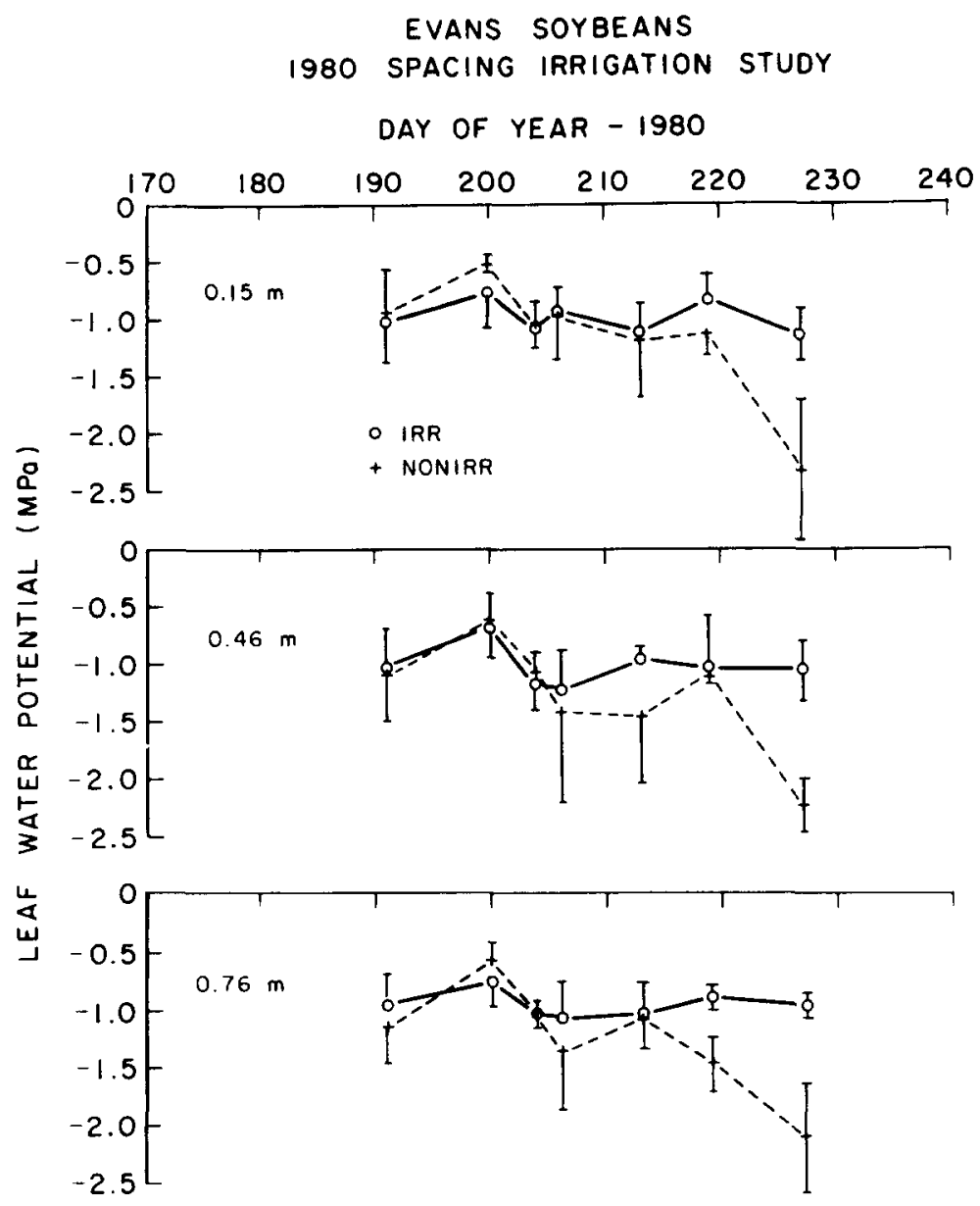

Fig. 4. Seasonal trends in the midday leaf water potential of the irrigated and non-irrigated soybeans for the $0.15 \cdot, 0.46-$, and $0.76-\mathrm{m}$ row spacings. Vertical bars represent \pm one standard deviation with overlapping bars omitted for clarity. 
mum value of +0.6 on the non-irrigated $0.15-\mathrm{m}$ row spacing. Similar trends were shown for the 0.46 - and $0.76-\mathrm{m}$ row spacings but of lesser magnitude. The trend between the TF-TA differences and the ET supported the suggestion that TF may be an indicator of the plant water stress and the plant's ability to meet the evaporative demand (Idso et al., 1980).

The trends in the ET, TA, and $\psi_{\ell}$ were as expected based on the soil water regimes. Throughout the season, the largest differences were between the irrigated and non-irrigated treatments at all three row spacings. The effect of row spacing was noted only early (DY 177) in the growing season when the midday ET was $0.35 \mathrm{~mm} / \mathrm{h}$ on the $0.15 \cdot \mathrm{m}$ row spacing as compared to 0.25

EVANS SOYBEANS

1980 SPACING IRRIGATION STUDY

DAY OF YEAR - 1980

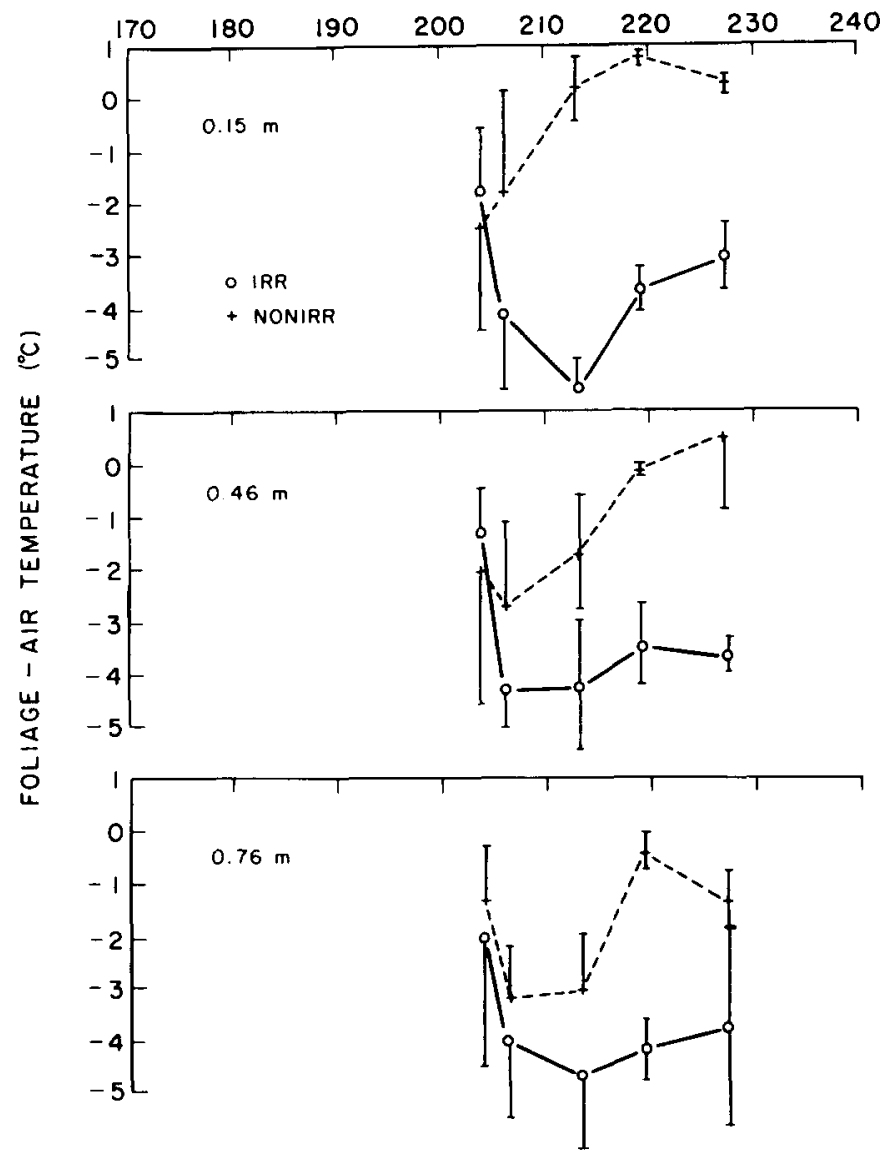

Fig. 5. Seasonal trends in the midday foliage temperature minus air temperature differences of the irrigated and non-irrigated soybeans at the $0.15-, 0.46-$, and $0.76-\mathrm{m}$ row spacings. Vertical bars represent \pm one standard deviation with overlapping bars omitted for clarity. 
$\mathrm{mm} / \mathrm{h}$ on the $0.76-\mathrm{m}$ row spacing. This difference in ET was apparently related to the development of the LAI, the light interception, and the available soil water. Once the light interception approached $100 \%$ on all row spacings, the differences between row spacings were evident only around DY 206. Following this time, only the differences due to irrigation were evident.

The effects of row spacing on the water use efficiency should reflect the effect of intermittent water stress and the resultant final yield. In this experiment, the yield data showed the largest difference due to irrigation on all row spacings and was expected based on the low soil water holding capacity. The analysis of variance showed the irrigated plots had yields significantly greater than the non-irrigated plots and there was no significant interaction between row spacing and water regime, i.e., the difference between irrigated and non-irrigated did not depend on row spacing. For the irrigated treatments, the yields, while not significantly different, were 3.35 , 3.09 , and $3.07 \mathrm{t} / \mathrm{ha}$ for the $0.15-, 0.46-$, and $0.76-\mathrm{m}$ row spacings, respectively. The corresponding yields for the non-irrigated treatments were 2.07, 1.97 , and $2.24 \mathrm{t} / \mathrm{ha}$. The slightly higher yields on the $0.15 \mathrm{-m}$ row spacing of the irrigated treatment may reflect the earlier increase in LAI and light interception as reported by Shibles and Weber (1966) and is in general agreement with the work of Taylor (1980), Mason et al. (1982), Taylor et al. (1982) and Reicosky et al. (1982). The slightly lower yields on the $0.15 \cdot \mathrm{m}$ and $0.46-\mathrm{m}$ row spacing compared to the $0.76-\mathrm{m}$ row spacing non-irrigated treatment may reflect the earlier soil water extraction resulting in less available water during the critical pod filling period. While these yield differences due to row spacing within a water regime are not significant statistically, they are in general agreement with the periodic measurements of ET and TFTA.

The small differences in measured ET, $\psi_{\ell}$ and TF due to row spacing appeared to interact with soil water regime. However, the precision of the measurements and the limited number of midday measurements preclude firm conclusions on the effects of row spacing from this study. These limited data indicate the need for more precise and frequent measurement of ET, $\psi_{\ell}$, and TF throughout the growing season to identify and characterize any row spacing-water stress effects over the entire season. Evidence has been presented for the importance of irrigation on the shallow sandy soils in west central Minnesota in a growing season with near normal rainfall.

\section{REFERENCES}

Alessi, J. and Power, J.P., 1982. Effects of plant and row spacing on dryland soybean yield and water-use efficiency. Agron. J., 74: 851-854.

Cooper, R.L., 1977. Response of soybean cultivars to narrow rows and planting rates under weed free conditions. Agron. J., 69: 89-92.

Cooper, R.L. and Lambert, J.W., 1965. Narrow rows and soybean yields in Minnesota. Minn. Agric. Exp. Sta. Farm Home Sci., 22 (4): 5-7. 
Idso, S.B., Reginato, R.J., Reicosky, D.C. and Hatfield, J.L., 1981. Determining soilinduced plant water potential depressions in alfalfa by means of infrared thermometry. Agron. J., 73: 826-830.

Mason, W.K., Rowse, H.R., Bennie, A.T.P., Kaspar, T.C. and Taylor, H.H., 1982. Responses of soybeans to two row spacings and two soil water levels. II. Water use, root growth and plant water status. Field Crops Res., 5: 15-29.

Pendleton, J.W., Bernard, R.L. and Hadley, H.H., 1960. Grow soybeans in narrow rows. Illino is Agric. Exp. Sta., Ml. Res., 2 (1): 3-4.

Reicosky, D.C. and Peters, D.B., 1977. A portáble chamber for rapid evapotranspiration measurements on field plots. Agron. J., 69: 729-732.

Reicosky, D.C., Rowse, H.R., Mason, W.K. and Taylor, H.M., 1982. Effect of irrigation and row spacing on soybean water use. Agron. J., 74: 958-963.

Safo-Kantanka, O. and Lawson, N.S., 1980. The effect of different row spacings and plant arrangements on soybeans. Can. J. Plant Sci., 60: 227-231.

Scholander, P.F., Bradstreet, E.D. and Hemmingsen, E.A., 1965. Sap pressure in vascular plants. Science, $184: 339-346$.

Shibles, R.M. and Weber, C.R., 1965. Leaf area, solar radiation interception and dry matter accumulation by soybeans. Crop Sci., $5: 575-578$.

Shibles, R.M. and Weber, C.R., 1966. Interception of solar radiation and dry matter production by various soybean planting patterns. Crop Sci., $6: 55-59$.

Taylor, H.M., 1980. Soybean growth and yield as affected by row spacing and by seasonal water supply. Agron. J., 72: 543-547.

Taylor, H.M., Mason, W.K., Bennie, A.T.P. and Rowse, H.R., 1982. Responses of soybeans to two row spacings and two soil water levels, I. An analysis of biomass accumulation, canopy development, solar radiation interception and components of seed yield. Field Crops Res., 5 : 1-14.

Timmons, D.R., Holt, R.F. and Thompson, R.L., 1967. Effect of plant population and row spacing on evapotranspiration and water use efficiency by soybeans. Agron. J., $59: 262-265$.

Van Bavel, C.H.M., 1966. Potential evaporation: the combination concept and its experimental verification. Water Resour. Res., 2: 455-467.

Weber, C.R., Shibles, R.M. and Byth, D.E., 1966. Effect of plant population and row spacing on soybean development and production. Agron. J., 58: 99-102. 